\title{
OBITUARY
}

\section{Professor Kenneth Fearon: 3 August 1960-3 September 2016}

European Journal of Clinical Nutrition (2017) 71, 1-2; doi:10.1038/ ejcn.2016.251

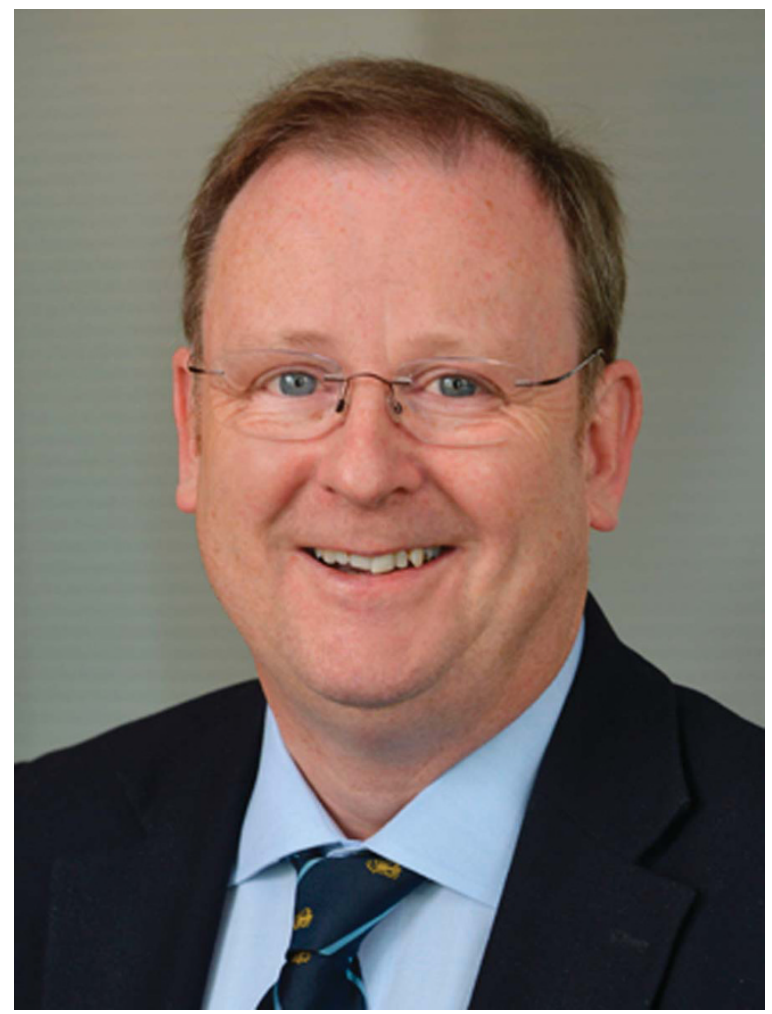

With the sudden demise of Professor Kenneth Christopher Fearon on 3 September 2016 the worlds of surgery, nutrition, cancer metabolism and enhanced recovery have lost one the best leaders of our times.

Ken Fearon was born and raised in Glasgow, Scotland. He studied medicine at the University of Glasgow, graduated with Honours in 1982. He trained in surgery and surgical oncology at Glasgow and Edinburgh and developed an interest in Surgical Oncology at an early stage of his career. He defended his thesis 'Mechanisms and Treatment of Cancer Cachexia' to be awarded the Doctor of Medicine (MD) degree by the University of Glasgow in 1986. After moving to Edinburgh and serving at different clinical and academic positions, he was awarded Professor of Surgical Oncology in 1999. He also held the post of Consultant Colorectal Surgeon at Western General Hospital, Edinburgh from 1993.

Ken was a devoted clinician and highly skilled colorectal surgeon, and called himself 'a doctor who could also operate'. Alongside his clinical development and career, from an early age he was also devoted to clinical surgical research. Starting with an interest in cancer cachexia, over the years he developed into a true translational researcher with publications ranging from clinical outcomes studies and large randomized clinical outcome trials to publishing papers of the studies of mechanisms at the molecular level in the world's highest ranking journals. The sum of Ken's contributions to cancer cachexia comprise a truly unique achievement in our time of increasingly higher specialization.

One of his most important contributions for the development of surgery was his leadership in the ERAS-Enhanced Recovery After Surgery-development. Together with Olle Ljungqvist he set out to 'place nutrition and metabolism back in the surgical agenda', and they invited friends and colleagues to form the ERAS study group in 2001 that developed into the ERAS Society in 2010, now a global network of expertize reaching all continents. ERAS is a multimodal evidence-based approach to perioperative care that has been shown to reduce recovery time and complications in major surgery by $30-50 \%$, thus, a good example of value-based health care of our times. By serving as the Chairman of the Board of the ERAS Society and being very much involved in research, guideline production and development of ERAS, Ken played a key leading role in this important development. With his extraordinary wisdom and intellectual sharpness, he would formulate the problems and set out to solve them or answer the questions raised.

The research highlights of Ken's career had a considerable span. Dating from the time of his earliest work, Ken was conversant with the experimental models of cancer cachexia and their strengths and limitations. However, Ken pressed the need to understand the human biology of cancer cachexia. In this domain Ken achieved the first large-scale study to begin to assess the heritable risk factors for cancer cachexia. Ken also steered metabolic studies of total energy expenditure and myofibrillar protein synthesis, using stable isotope tracer techniques, and working within his surgical practise collected muscle biopsies for intensive biochemical, molecular and morphological investigation. Ken was a great leader in the ongoing evolution of cachexia clinical trials, himself mounting several large international randomized Phase III studies. A study designed by Ken which is framed, like ERAS, around a multidisciplinary approach, is currently open to accrual at international sites-the Multimodal Intervention for Cachexia in Advanced Cancer Patients Undergoing Chemotherapy (MENAC) NCT02330926 trial. Ken's input was critical to the design and implementation of new trials, and he spoke with a clear voice about the need for the investigators and regulatory authorities to define approvable therapeutic end points.

Fearon K et al. Lancet oncology 2011: 12(5):489-495, Definition and classification of cancer cachexia, an international consensus, is a landmark work cited over 1100 times to date, and our future road map.

Ken was a world-class speaker and as such invited worldwide. $\mathrm{He}$ won numerous awards including the 1991 Sir David Cuthbertson Award and the 2011 Arvid Wretling Award from ESPEN, the European Society for Clinical Nutrition and Metabolism, as well as an honorary doctorate at Örebro University, Sweden in 2015.

We, who worked close to him and became his friends, found in Ken a generous, kind and humble man, always true to his friends and his mission. Outside work, he was highly knowledgeable, and fostered a variety of interest ranging from flowers and gardening, through music, literature and art, to golf and sports. As he was also a superb cook and wine connoisseur, and it was always a pleasure 
to enjoy his warm hospitality in his home with his wife Marie Fallon and their two children Christopher and Katie.

It is with great shock and sadness we learned about his sudden demise at the height of his career and mission, and he will always remain in our memory. In the loss of our dear friend and colleague, our thoughts go to his family.
O Ljungqvist ${ }^{1}$ and VE Baracos ${ }^{2}$ ${ }^{1}$ Department of Surgery, Faculty of Medicine and Health, School of Health and Medical Sciences, Örebro University, Örebro, Sweden and ${ }^{2}$ Division of Palliative Care Medicine, Department of Oncology, Cross Cancer Institute, University of Alberta, Edmonton, Alberta, Canada E-mail: Olle.Ljungqvist@ki.se 